Artigo Original

\title{
Vulnerabilidade natural à contaminação do aquífero Alter do Chão na área urbana de Manaus, Amazonas, Brasil
}

\author{
Natural vulnerability to contamination of the aquifer Alter do Chão in urban area of Manaus, \\ Amazonas, Brazil
}

\author{
Miqueias Lima Duarte', Heron Salazar Costa", Tatiana Acácio da Silva'"', Mariano Vieira dos Santos ${ }^{\text {Iv }}$
}

\section{Resumo}

A utilização dos recursos hídricos subterrâneos cresce em função do crescimento populacional e da atividade produtiva, aumentando a demanda por água de qualidade, ao mesmo tempo em que crescem os riscos de sua contaminação. $\mathrm{O}$ presente estudo avaliou a vulnerabilidade à contaminação do aquífero Alter do Chão na área urbana do município de Manaus, com a aplicação do método GOD (Groundwater occurrence Overall Lithology of the unsaturated zone, Depth of the water table). O emprego do método possibilitou o mapeamento de áreas diferenciadas nas três classes de vulnerabilidade. A baixa vulnerabilidade à contaminação foi predominante $(0,41 \%)$, seguida pela média vulnerabilidade $(0,35 \%)$ e alta vulnerabilidade à contaminação $(0,24 \%)$. A distribuição das classes de alta vulnerabilidade na área de estudo é motivo de preocupação, pelo potencial de contaminação associado o atual uso e ocupação do solo, também em função da direção do fluxo subterrâneo.

Palavras-chave: Aquífero Alter do Chão; Método GOD; Fragilidade ambiental

\section{Abstract}

The use of underground water resources grows due to population growth and productive activity, increasing the demand for quality water, while growing the risks of its contamination. The present study evaluated the vulnerability to contamination of the Alter do Chão aquifer in the urban area of the municipality of Manaus, with the application of the method GOD (Groundwater occurrence Overall Lithology of the unsaturated zone, Depth of the water table). The use of the method allowed the mapping of differentiated areas in the three classes of vulnerability. The low vulnerability to contamination was predominant $(0.41 \%)$, followed by the mean vulnerability $(0.35 \%)$ and high vulnerability to contamination $(0.24 \%)$. The distribution of the classes of high vulnerability in the study area is a cause for concern, due to the potential contamination associated with the current use and occupation of the soil, also due to the direction of the underground flow.

Keywords: Alter do Chão Aquifer; GOD Method; Environmental fragility 


\section{Introdução}

Na Amazônia, é crescente a perspectiva de exploração dos depósitos de água subterrânea devido as vantagens práticas e econômicas apresentadas quanto a sua captação, excelente qualidade e abundância (AZEVEDO, 2006). Em razão dessas vantagens e por outros motivos, vários núcleos urbanos amazônicos têm passado a utilizar exclusivamente as fontes subterrâneas para o abastecimento de água (DUARTE et al., 2016; DUARTE et al., 2017; DUARTE et al., 2018). Essa opção fica clara ao se analisar os dados do Sistema Nacional de Águas (ANA, 2010) referentes ao Estado do amazonas, onde 70\% dos municípios são abastecidos por fontes subterrâneas, e demais cidades como Manaus, Manacapuru, Lábrea e Coari, possuem um sistema de abastecimento misto, com captura de águas superficiais e subterrâneas.

O Instituto Brasileiro de Geografia e Estatística - IBGE (2018), por meio do levantamento censitário detectou que na área urbana de Manaus, 25,6\% das residências não possuem abastecimento a partir da concessionaria autorizada, isso faz com que a obtenção de água ocorra de forma desordenada, muito provavelmente por meio de poços rasos sem a garantia dos padrões técnicos ideais para o tipo de estrutura construtiva necessária (FOSTER et al., 2016).

Os principais aquíferos que ocorrem e são explorados para abastecimento público no Estado do Amazonas são Içá, Alter do Chão e os relacionados às coberturas aluvionares recentes e antigas (MAIA, 2010). O sistema de aquífero Alter do Chão encontrar-se livre no meio urbano do município de Manaus, o que o caracteriza como susceptível à contaminação, pois apresenta nível estático pouco profundo, sendo mais facilmente alcançado pela poluição antrópica (AGUIAR e MOURÃO, 2012). Trabalhos desenvolvidos no meio urbano do município de Manaus já apontam alterações nos parâmetros físicos, químicos e biológicos nas águas distribuídas pelos poços pesquisados, apresentando valores acima do aceito pelos padrões da legislação vigente no Brasil (COSTA et al., 2014; SANTANA e ZEFERINO, 2008).

O estudo da vulnerabilidade à contaminação do aquífero é um instrumento essencial para uma gestão adequada dos recursos hídricos e o ordenamento territorial, pois, por meio deste, conforme sugere Santos et al. (2010), é possível conhecer a fragilidade do manancial, o que de fato possibilita o melhor planejamento do uso e ocupação da área. Vários estudos sobre esse tema têm sido desenvolvidos. No Brasil, destacando-se Cutrim e Campos (2010); Feron e Reginato (2014); Meira et al. (2014), Duarte et al. (2016). Em outros países, podemos citar Insaf et al. (2005); Baalousha (2010); Abdelmadjid e Omar (2013). A quantidade e a qualidade de tais estudos é uma demonstração do reconhecimento da importância que esse assunto tem no atual contexto socioambiental.

A análise da vulnerabilidade também serve como elemento de balizamento para ações gerenciais que visem à gestão racional dos mananciais subterrâneos, bem como para a gestão, por parte dos órgãos públicos responsáveis pela implementação de políticas de controle e preservação dos recursos hídricos (SANTOS et al., 2010; DUARTE et al., 2016).

Dentre as técnicas utilizadas na avaliação da vulnerabilidade de aquíferos, podemos destacar os seguintes métodos: índice DRASTIC desenvolvido por Aller et al. (1987) e GOD proposto por Foster e Hirata (1988). O método DRASTIC fornece um índice de potencial à contaminação de águas subterrâneas a partir de uma valoração relativa em função da profundidade do lençol freático (D), recarga do aquífero (R), tipo do aquífero (A), tipo de solos (S), topografia (T) impacto sobre a zona insaturada (I) e condutividade hidráulica (C) (parâmetros que compõe o método DRASTIC). Por outro lado, o método GOD por avaliar a fragilidade de aquíferos levando em consideração parâmetros de fácil obtenção, tais como o grau de confinamento do aquífero $(G)$, a litologia da camada insaturada $(\mathrm{O})$ e a profundidade do nível da água (D) (parâmetros que compõe o método GOD), tornou-se um método bastante difundido na América Latina e Caribe.

A aplicação do método GOD tem sido amplo em diversas regiões do Brasil. No sul do país, por exemplo, o método foi utilizado em trabalhos como os desenvolvidos por Reginato e Ahlert (2013); Borba et al. (2014); Carvalho et al. (2014); Feron e Reginato (2014); Silvério da Silva et al. (2014). Na região Nordeste, observa-se os trabalhos de Ribeiro et al. (2011); Oliveira e França-Rocha (2013). No Centro-Oeste, Cutrim e Campos (2010); Meira et al. (2014); Júnior et al. (2015). E na região Norte, Duarte et al. (2016); Duarte et al. (2017) e Duarte et al. (2018).

Manaus, assim como boa parte das grandes metrópoles brasileiras já teve seus problemas de desordem de uso dos seus espaços urbanos demonstrados por trabalhos desenvolvidos por Costa et al. (2012) e Rabello e Rodrigues (2013). A carência de informações sobre a vulnerabilidade das águas subterrâneas que abastece o município associada ao desordenamento do uso dos espaços urbanos justifica a realização de estudos desse tipo. A partir do exposto, e considerando a crescente utilização dos recursos hídricos no município de Manaus, o presente trabalho foi desenvolvido com o objetivo de avaliar a vulnerabilidade à contaminação das águas subterrâneas na área urbana do município, aplicando-se o método GOD descrito por Foster et al. (2006).

\section{Material e Método}

\section{1 Área de Estudo}

A área abrangida nesse estudo compreende o perímetro urbano do município de Manaus, cujo retângulo envolvente sob coordenadas $2^{\circ} 58^{\prime} 48.60^{\prime \prime}$ Sul; $60^{\circ} 5^{\prime} 26.07^{\prime \prime}$ Oeste e $3^{\circ} 8^{\prime} 3.45^{\prime}$ 'Sul; $59^{\circ} 55^{\prime} 44.45^{\prime \prime}$ Oeste, está situado na confluência dos rios Negro e Solimões (Figura 1).

Segundo dados do IBGE (2010), o município de Manaus possui população de 1.792.881 habitantes, (estimativa de 2.145.444 habitantes para 2018) com uma densidade demográfica de 158,06 hab. $\mathrm{km}^{-2}$, o que a caracteriza como a cidade com maior adensamento populacional da região Norte. O que, de certo modo, significa pressão sobre o espaço territorial com consequente expansão da área urbanizada. 
Figura 1 - Localização da área de estudo, destacando o perímetro urbano do município de Manaus, no estado Amazonas



Fonte: Elaborado pelo autor

Não diferente das demais capitais brasileiras, a ausência de planejamento urbano sistemático e a falta de controle relacionado ao crescimento da cidade ocasionaram sérios problemas ambientais na área urbana do município de Manaus. Atualmente, as grandes concentrações populacionais encontram-se nas zonas Leste e Norte, as quais são atualmente, responsáveis pelo agravamento de problemas relacionados à ocupação desordenada do espaço urbano, remoção da cobertura vegetal, contaminação do solo, poluição dos corpos d'água bem como poluição das águas subterrâneas e deficiência do saneamento básico (COSTA et al., 2012; RABELLO e RODRIGUES, 2013).

\subsection{Caracterização Geológica e Hidrogeológica}

Segundo informações compiladas no Mapa geológico do Amazonas (CPRM, 2019) no município de Manaus ocorrem afloramentos de quatro unidades geológicas: a Formação Alter do Chão (0,80\%), Depósitos Aluvionares $(0,04 \%)$, Prosperança $(0,01 \%)$ e a Formação Trombetas $(0,15 \%)$. Considerando apenas o meio urbano do município, a Formação Alter do Chão é a única aflorante.

A Formação Alter do Chão ocorre nas Bacias Sedimentares do Solimões e Amazonas, alcançando nesta última até 1.250 metros de espessura (CUNHA e GONCALVES, 2007), ela é representada por arenitos e pelitos avermelhados, relacionados a um sistema deposicional continental do Cretáceo Superior. Aparece assentada discordantemente sobre os calcários da Formação Nova Olinda, de idade carbonífera. Em sua sucessão inferior é constituída predominantemente por arenitos, e em sua seção superior de constituição pelítica (AGUIAR e MOURÃO, 2012). No estudo de perfilagem geofísica de poços e informações litológicas de amostragem de calha, realizado por Souza (2006), na área urbana de Manaus, ficou demonstrada a ocorrência de fácies sedimentares arenosa, argilosa, arenoargilosa e o conjunto de rochas denominados "Arenito Manaus", todos, apresentando indícios de formação por deposição em ambiente fluvial e fluviodeltaico.

Em relação ao sistema de aquíferos, o aquífero Alter do Chão é um dos maiores sistemas de águas subterrâneas do Brasil (ANA, 2010). Na área urbana de Manaus, segundo Aguiar e Mourão (2002), o sistema de aquífero é do tipo livre, possuindo espessura aproximada de $200 \mathrm{~m}$, dos quais, $175 \mathrm{~m}$ estão saturados, tendo profundidade média do nível d'água de aproximadamente $30 \mathrm{~m}$, com maiores profundidades nos setores sudeste e nordeste, correspondendo a quase toda a porção oriental da cidade, no entanto, para oeste, o nível d'água torna-se mais raso, chegando a aflorar em alguns locais, como no setor noroeste.

Os poços profundos perfurados da área urbana do município de Manaus, comumente apresentam vazões superiores a $100 \mathrm{~m}^{3} \mathrm{~h}^{-1} ;$ com capacidade específica média de $5,55 \times 10-4 \mathrm{~m}^{2} \mathrm{~s}^{-1}$ e a transmissividade de $1,30 \times 10^{3}$ $\mathrm{m}^{2} \mathrm{~s}^{-1}$ (SILVA e BONOTTO, 2000; MAIA, 2010). 


\subsection{Base de Dados para Confecção dos Mapas}

Para o desenvolvimento deste estudo, contou-se com dados disponíveis no website do Sistema de Informações de Águas Subterrâneas/SIAGAS (SIAGAS, 2019) do Serviço Geológico Brasileiro (CPRM). Esses dados foram obtidos entre janeiro e fevereiro de 2019. Para selecionar os registros no website do SIGAS levou-se em consideração a disponibilidade dos seguintes dados: a identificação dos poços (ID), coordenadas UTM, nível estático, nível dinâmico, formação geológica e perfil litológico descritivo, bem como o período de instalação e situação atual dos poços. A quantidade de registros encontrados que apresentavam esses requisitos foi de 1.492 poços.

Com base nos registros georreferenciados dos poços foi realizada uma seleção de forma randômica com objetivo de se ajustar uma malha mais homogeneamente distribuída. Essa seleção foi realizada em ambiente SIG (QGIS 3.2.3 versão "Bonn") sem conhecimento das características hidrogeológicas apresentadas em cada poço, apenas sabendo-se a posição geográfica. O critério adotado para distribuição da malha amostral aleatória foi com distância mínima de 500 metros e máxima de 1.000 metros, esse filtro gerou uma malha amostral com poços (208 registros) distribuídos em toda área de estudo.

Para a extração da rede de drenagem presente na área urbana de Manaus, foram utilizados dados do Shuttle Radar Topography Mission (SRTM) com resolução espacial de 30 metros disponibilizado pelo United States Geological Survey (USGS, 2019) via website, sendo obtidas quatro cenas (s04_w061; s04_w060; s03_w061; s03_w060).

Na confecção cartográfica, utilizou-se a base de dados no formato JPEG (Joint Photographics Experts Group) obtida junto ao website do Instituto Municipal de Planejamento Urbano - IMPLURB (2018) de Manaus, na seção "Mapas Temáticos", e malha do setor censitário disponibilizado pelo Instituto Brasileiro de Geografia e Estatística/IBGE.

\subsection{Descrição e Aplicação do Método GOD}

O método GOD proposto por Foster e Hirata (1988) e modificado por Foster et al. (2006), baseia na análise de três parâmetros. O índice "G" (Groundwater hydraulic confinement) que é o grau de confinamento do aquífero, índice "O" (Overlaying strata) que corresponde ao tipo de litologia encontrada na zona não saturada, e "D” (Depth to groundwater table) que corresponde á profundidade do nível d'água.

Cada parâmetro possui um índice de acordo com suas características especificas: "G", que corresponde ao grau de confinamento do aquífero, varia de 0 a 1 . "O”, que se refere ao tipo litológico, varia de 0,4 a 1. "D”, que corresponde a profundidade do nível estático do aquífero, varia entre 0,6 e 1 . O índice final de vulnerabilidade do aquífero corresponde ao produto dos três índices, onde valores mais próximos de 0 corresponde a menores índice de vulnerabilidade, enquanto valores mais próximos de 1 corresponde a maiores índices de vulnerabilidade.

No caso do presente estudo, por se tratar de um sistema de aquífero livre, apresentando cobertura intercalada de argilitos e arenitos, foi atribuído índice 0,9 para os pontos que se apresentavam recoberto por arenitos, e em locais recobertos por argilitos e "Arenitos Manaus" o índice empregado ao parâmetro "G" foi 0,6.

Com respeito à litologia da camada insaturada (parâmetro “O”), a análise dos perfis geológicos dos poços pesquisados revelou a predominância de frações granulométricas: argilito, arenito e siltitos. Com base nesses registros, foram atribuídos os índices de acordo com sua constituição, sendo estes: 0,6 (argilito e Arenitos Manaus), 0,65 (argilito/arenito ou siltito/arenito) e 0,8 (arenitos).

Para o parâmetro "D”, considerando que na área de estudo a profundidade variou entre 5 a 109 metros, foram atribuídos os seguintes índices: 0,6 (profundidades $>50$ metros), 0,7 (profundidades entre 20 a 50 metros) e 0,8 para profundidades inferiores a 20 metros.

\subsection{Processamento dos Dados}

O processamento dos dados foi realizado com auxílio do Sistema de Informação Geográfica (QGIS versão 3.2.3 Bonn), onde foi realizada uma interpolação dos índices "G" “O” e "D" aplicando-se o método Inverso Ponderado da Distância (Inverse Distance Weighting - IDW) conforme descrito por Duarte et al., (2017). O índice de vulnerabilidade à contaminação foi obtido por meio da ferramenta Calculadora Raster do QGIS, sendo realizada uma multiplicação entre os parâmetros "G" “O” e "D" interpolados (DUARTE et al., 2017; DUARTE et al., 2018).

A extração da rede de drenagem da área de estudo foi realizada com auxílio do conjunto de ferramentas SAGA no QGIS. Onde foram utilizados os algoritmos Fill sinks para correção do SRTM, e o algoritmo Channel network and drainage basins, para extração da rede de drenagem (Channels).

$\mathrm{Na}$ confecção cartográfica, adotou-se o sistema de coordenadas Universal Transversal de Mercator (UTM), Datum SIRGAS 2000, Zona 21S.

\section{Resultados e Discussão}

Na área urbana do município de Manaus, observouse que o aquífero Alter do Chão possui vazão média de $78,72 \mathrm{~m}^{3} \cdot \mathrm{h}^{-1}$, e profundidade média do nível estático de 27,65 metros o que caracteriza como bom produtor de água. A Figura 2 exibe os perfis litológicos da secção transversal A - A' (Figura $2 \mathrm{~A}$ ) e da secção longitudinal B - B' (Figura 2B). Na secção transversal A - A' é possível verificar, na profundidade compreendida entre 120 a 80 metros, a predominância de depósitos sedimentares constituídos de arenito na região central, limitada ao sul e ao norte por afloramentos de argilito. Nas profundidades subsequentes, entre 80 a $40 \mathrm{~m}$ não apresentam um padrão definido, ocorrendo camadas de arenito intercaladas por argilitos, e em alguns casos a presença de arenito silitificado, a exemplo do Poço nº 1300006212 . 
A secção longitudinal B - B' apresenta em predominância, afloramento de argilito na parte superior, apenas um afloramento de arenito ocorrendo a partir do Poço no 1300006212 sentido B'. Como observado no perfil A-A', o perfil B-B' apresenta camadas intercaladas de arenito/argilito, característico da Formação Alter do Chão, depositados em ambiente fluvial e fluviodeltaico.

A Figura 3 apresenta o mapa topográfico (Figura 3A), de nível estático dos poços (Figura 3B) e da superfície potenciométrica (Figura 3C). O mapa referente a superfície potenciométrica foi elaborado com base na subtração da topografia do nível estático do sistema aquífero. Em relação à carga potenciométrica apresentada na Figura 3C, observouse que as maiores cargas estão em torno de 59 metros, e localizadas nas partes mais elevadas da área de estudo, enquanto que as menores cargas estão entorno de 3 metros e ocorrem principalmente nas partes mais baixas do terreno, predominantemente às margens do Rio Negro e Amazonas, e demais drenagens na área urbana, assim como observado em estudos desenvolvidos por Aguiar e Mourão (2012).

A Figura 4 (A, B e C) apresenta a distribuição espacial dos parâmetros GOD obtido para a área de estudo. $\mathrm{Na}$ Figura $4 \mathrm{~A}$ está representada a distribuição espacial do valor atribuído ao parâmetro grau de confinamento do aquífero $(G)$. Observa-se a predominância do índice 0,6 em $73,2 \%$ da área analisada. A configuração espacial irregular apresentada nesse parâmetro está, de certa forma, associada à geomorfologia do terreno, uma vez que é possível se presumir uma semelhança de distribuição entre ambos.

A Figura 4B apresenta a distribuição espacial do valor atribuído ao parâmetro litologia da camada insaturada (O). Observa-se a predominância do valor 0,65 em 62,4\% da área. Esse valor foi atribuído à ocorrência de litologia constituída por arenito/argilito e/ou arenito/siltito. O restante da área está marcado pela ocorrência de litologia arenosa $(0,8)$ distribuída em $21,5 \%$ da área, seguido pela litologia argilosa $(0,6)$ em $16,1 \%$.

A distribuição espacial do valor atribuído ao parâmetro $\mathrm{D}$, o qual refere-se à profundidade até o lençol freático está apresentada na Figura 4C. Nesse mapa chama-se a atenção a distribuição do valor 0,8 , o qual é imposto a situações em que o lençol freático se apresenta em profundidades entre 5,0 a $20,0 \mathrm{~m}$. A ocorrência de áreas de valor 0,7 para a profundidade entre 20 a 50 m é observada predominantemente na zona leste e norte, no entanto, também se observa pequenas porções na zona sul. $O$ valor 0,6 se estende predominantemente na porção central da área, cuja profundidade do lençol freático apresenta-se superior a $50,0 \mathrm{~m}$.

A multiplicação dos parâmetros do método GOD

Figura 2 - Seção geológica (A: transversal, B: longitudinal) da área de estudo elaborada a partir de dados do SIAGAS (2019), com interseção no poço em destaque (Poço - 1300006212)

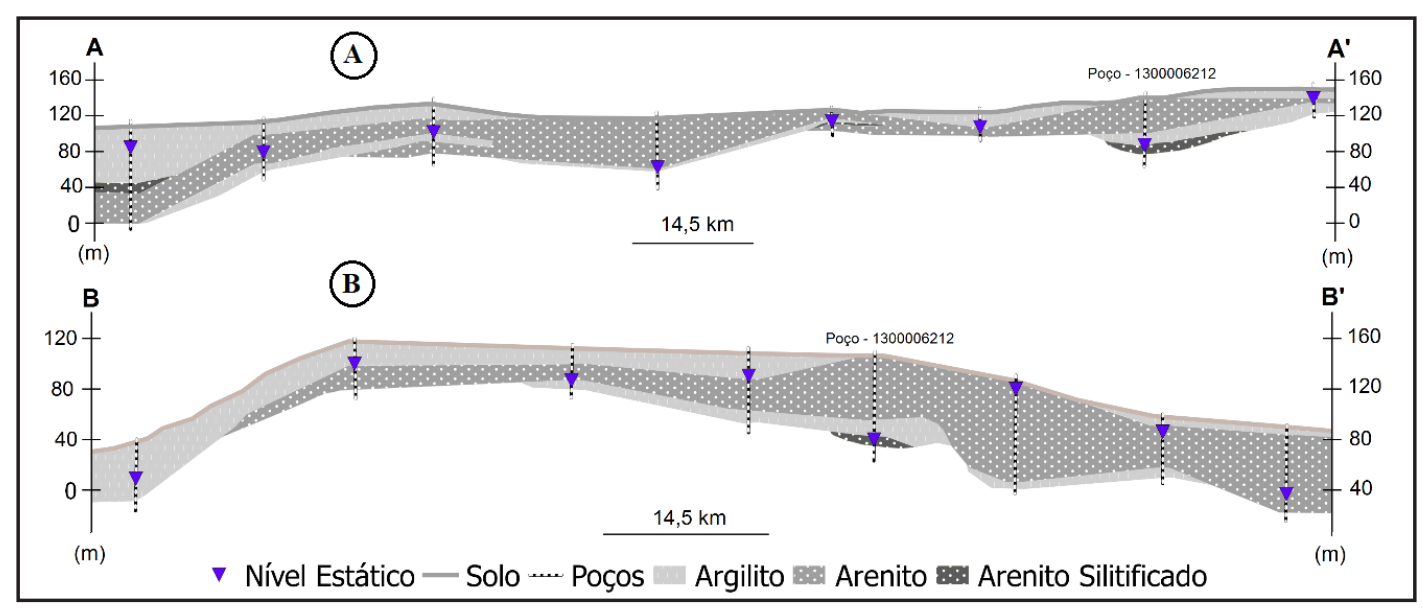

Figura 3 - Topografia (A), nível estático (B) e superfície potenciométrica (C) da área urbana de Manaus

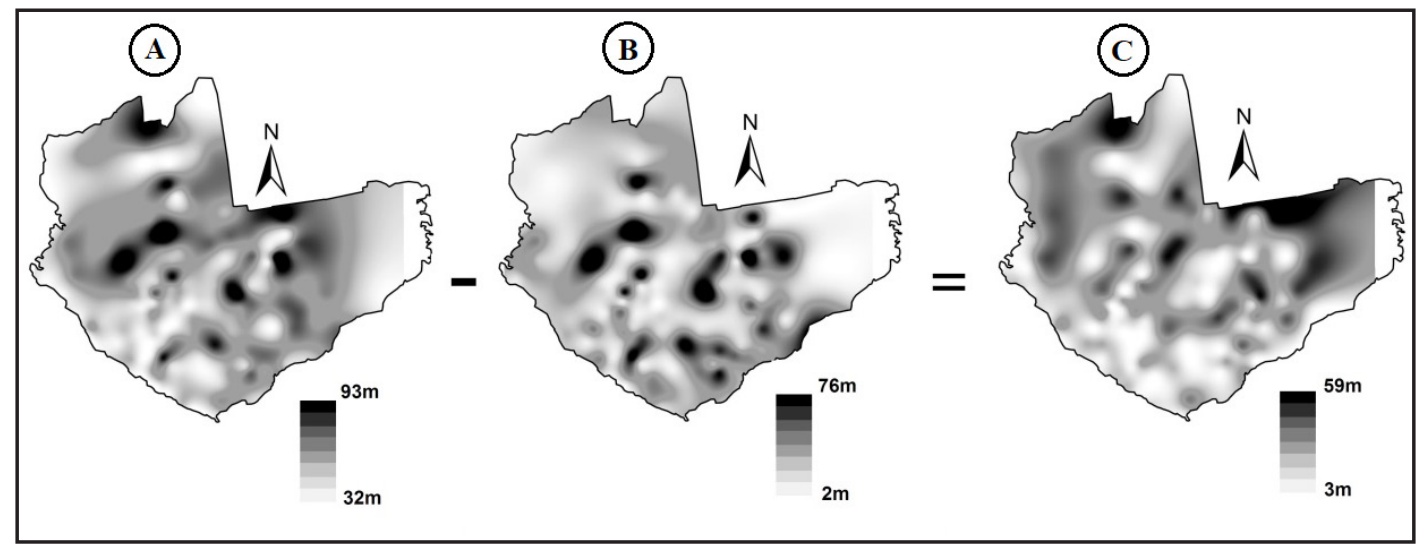

Fonte: Elaborado pelo autor a partir de dados do SIAGAS (2019) 
Figura 4 - Distribuição espacial dos parâmetros GOD na área de estudo

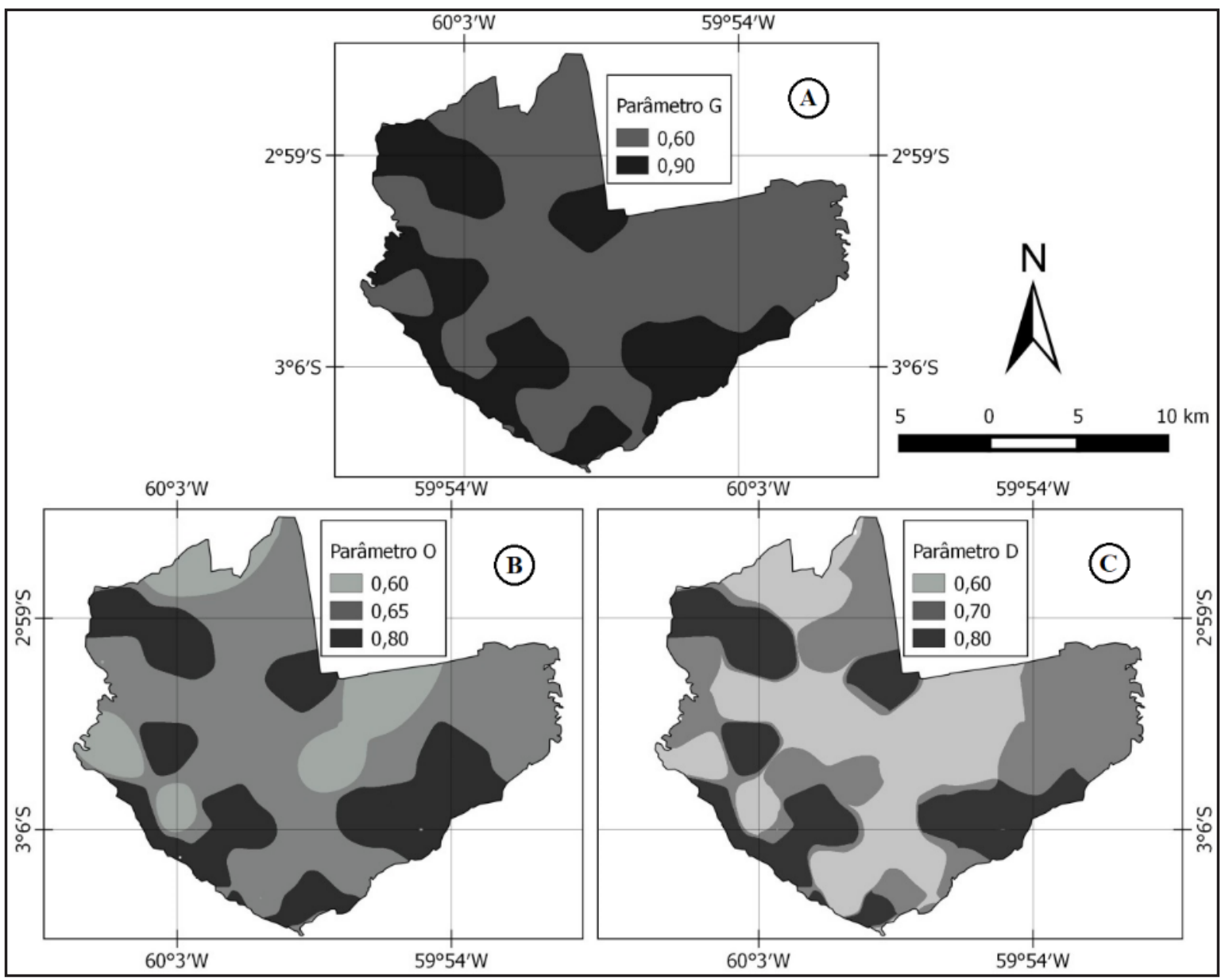

em ambiente SIG possibilitou obter-se o índice de vulnerabilidade à contaminação do aquífero, com isso foi feita a distribuição das classes de vulnerabilidade na área de estudo que está disposta na Figura 5. As três classes de vulnerabilidade à contaminação: baixa, média e alta, apresentaram os seguintes valores de ocorrência percentual: baixa vulnerabilidade, em $41 \%$ da área; média vulnerabilidade, em $35 \%$ da área, e; alta vulnerabilidade, em $24 \%$ da área.

Conforme a ocorrência e distribuição das classes de vulnerabilidade apresentada na Figura 5, é possível observar que a predominância de baixa vulnerabilidade à contaminação do sistema de aquífero na área ocorre predominantemente na parte central, desde a zona norte até a zona sul da área urbana de Manaus, estendendose até a zona oeste. A baixa vulnerabilidade observada pode estar relacionada com a sequência de camadas de sedimentos de granulação fina que é constituída em sua maioria de silte/argila, que por sua heterogeneidade, pode apresentar baixa porosidade e permeabilidade. Nesse caso, a granulometria menor preenche os espaços dos arenitos, de maior granulometria, reduzindo a permeabilidade local, o que pode servir como proteção contra a infiltração de poluentes, dificultando a locomoção do mesmo no meio, e deste modo, agregando baixa vulnerabilidade à contaminação nessas áreas (BARCHA, 1980; FOSTER et al., 2006).

Por outro lado, nota-se que a ocorrência de aglomerações que apresentaram média e alta vulnerabilidade à contaminação encontram-se distribuídas principalmente no entono do Rio Negro, Rio Amazonas e Igarapé TarumãAçu. Nessas áreas, a presença de camada confinante constituída apenas por arenitos, juntamente com o nível estático pouco profundo, acarretou em maiores índices de vulnerabilidade. Tais características hidrogeológicas podem pôr em risco à qualidade do manancial nesses locais, uma vez que podem ser facilmente alcançados por poluentes, devido à facilidade de percolação. Tal situação pode ser considerada mais preocupante ao se levar em conta que a soma das ocorrências das duas classes de vulnerabilidade perfaz cerca de $59 \%$ da área.

A informação gerada por esse trabalho ganha maior importância com a identificação de pontos potências de geração de carga contaminante, bem como o cruzamento com a provável direção de fluxo de água subterrâneas local, uma vez que isso possibilitará um melhor planejamento de uso e ocupação da área. A Figura 6 apresenta um mapa com os pontos potenciais de contaminação e representação da direção do fluxo de águas subterrâneas na área de estudo.

Observou-se dois padrões de direção de fluxo subterrâneo na área urbana do município. O primeiro diz respeito ao fluxo regional (da região norte para a região sul) e o segundo diz respeito aos fluxos secundários, onde as linhas de escoamento estão orientadas na direção 
Figura 5 - Mapa de vulnerabilidade à contaminação do aquífero

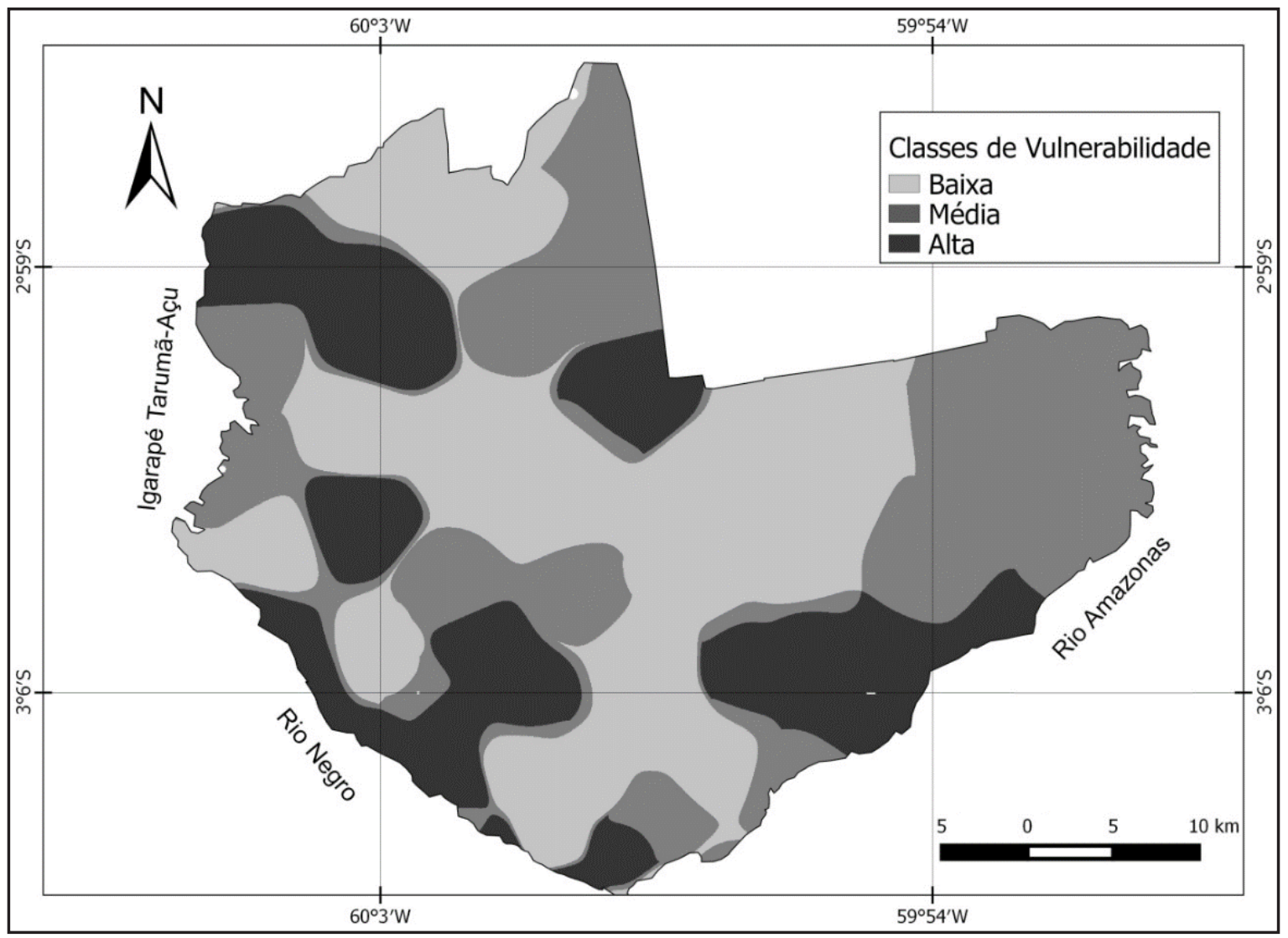

Fonte: Resultado da aplicação do método GOD, utilizando dados compilados pelo autor

Figura 6 - Mapa de pontos potenciais de contaminação e representação da direção do fluxo de águas subterrâneas na área de estudo

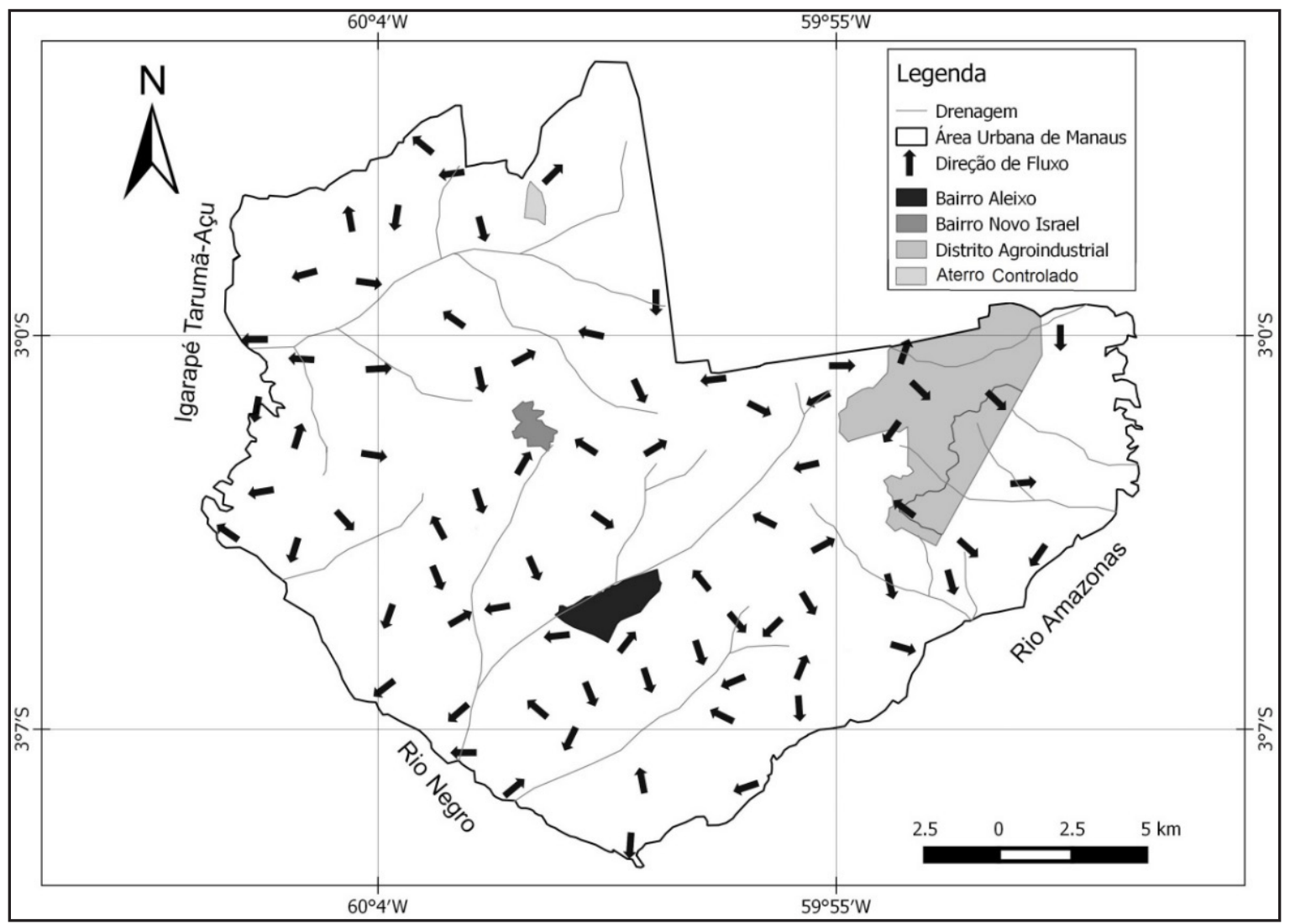


similar à rede de drenagem superficial, sugerindo um comportamento típico de aquíferos livres (conforme apresentado na Figura 6). Ambos podem apresentar características distintas de dispersão de poluentes em caso de contaminação do aquífero.

O bairro Novo Israel e Aleixo, bem como o Distrito Agroindustrial e o atual aterro controlado de Manaus (Figura 6) são caracterizados como áreas com um grande potencial de geração de carga contaminante. Na década de 80 , o local onde fica localizado o bairro de Novo Israel, na região norte da área urbana de Manaus, foi ponto de deposição de resíduos do município (antigo lixão), nesse local, observa-se que a direção de fluxo indica que existe altos índices de bombeamento de água, o que requer maiores cuidados quanto o uso da água para consumo, uma vez que possivelmente o manancial pode estar poluído em função da carga de contaminante depositada no antigo lixão.

A área onde fica localizado o atual aterro controlado do município (localizado no $\mathrm{km} 18$ da rodovia AM 010) e o Distrito Agroindustrial (localizado na região leste) do município apresentam alto potencial à contaminação do aquífero, uma vez que as atividades desenvolvidas nesses locais possuem potencial de geração de carga contaminante, além de estarem localizados em uma região de recarga local do sistema de aquífero, podendo ser um ponto de entrada de contaminante.

\section{Considerações Finais}

O resultado obtido com o desenvolvimento desse estudo destacou a predominância de áreas com média a alta vulnerabilidade à contaminação do sistema de aquífero sob a área urbana de Manaus, pois juntas perfazem $0,59 \%$ do total da superfície abrangida no estudo. Considerando-se a ocorrência isolada de cada faixa, predominou a baixa vulnerabilidade, ocorrendo em $0,41 \%$ da área, seguida da média, ocorrendo em $0,35 \%$ da área. A maior contribuição para ocorrência de alta vulnerabilidade, mesmo que em menor percentual pode ser atribuído ao afloramento de menores secções constituídas por arenitos da Formação Alter do Chão.

O estudo da predominância de fluxo da área indicou que existe, de modo geral, uma tendência de direção de fluxo da região norte para a região sul, além disso, também existe tendência de fluxos secundários, característicos de aquíferos livres. O que é muito grave ao se considerar que na porção norte ocorrem áreas com elevada carga de contaminação, como o bairro Novo Israel, por ter servido como depósito dos resíduos sólidos urbanos, por abrigar o Distrito Industrial, e por não existir um sistema de tratamento dos efluentes que são ali liberados.

Levando em conta os resultados obtidos, é de suma importância à adoção de políticas públicas que visem o melhor planejamento da utilização do recurso hídrico subterrâneo na área, uma vez que a altas taxas de bombeamento podem comprometer a qualidades do manancial.

\section{Referências}

ABDELMADJID, B.; OMAR, S. Assessment of groundwater pollution by nitrates using intrinsic vulnerability methods: A case study of the Nil valley groundwater (Jijel, NorthEast Algeria). academicJornals. v. 7. n. 10. p. 949-960. 2013.

AguiAR, C. J. B.; MOURÃO, M. A. A. Projeto Rede Integrada de Monitoramento das Águas Subterrâneas: relatório diagnóstico Aquífero Alter do Chão no Estado do Amazonas. Belo Horizonte: CPRM - Serviço Geológico do Brasil, p. 1-30. 2012.

ALLER, L.; BENNET, T.; LEHR, J. H.; PETTY, R. J. DRASTIC: a standardized system for evaluating groundwater pollution potencial using hydrogeologic settings. (U.S. EPA Report 600/2-85/018). 1987.

ANA - Agência Nacional de Águas, 2019. Sistema de Aquíferos. Disponível em: http:// metadados.ana.gov.br/geonetwork/srv/pt/metadata. show?id=150\&currTab=simple, Acessado em: 01/01/2019.

ANA. 2010. Atlas Brasil. Abastecimento Urbano de Água: panorama nacional/Agência Nacional de Águas. Engecorps/Cobrape - Brasília. p. 72.

AZEVEDO, R. P. Uso de água subterrânea em sistemas de abastecimento público de comunidades na várzea da Amazônia central. Acta Amazonica. v.36. n. 3. p. 313-320. 2006.

BAALOUSHA, H. Assessment of a groundwater quality monitoring network using vulnerability mapping and geostatistics: A case study from Heretaunga Plains, New Zealand. Agricultural Water Management. v. 97. p. 240-246. 2010.

BARCHA, S. F. Aspectos geológicos e províncias hidrogeológicas da Formação Bauru na região norteocidental do Estado de São Paulo. Tese (Livre Docência) -Instituto de Biociências, Letras e Ciências Exatas, Universidade Estadual Paulista, São José do Rio Preto, 1980. p. 209.

BORBA, W. F.; KEMERICH, P. D. C.; FILHO, L. L. D. V.; PRETTO, P. R. P.; FLORES, C. E. B; FRANÇA, J. R; HINTEHOLZ, D. Vulnerabilidade do aquífero à contaminação no município de Seberi/RS. Revista Monografias Ambientais. v. 14. p. 2960-2966. 2014.

CARVALHO, C. M.; ROCHA, N. S.; NUNES, D, S; CRUZ, R, C. Avaliação da vulnerabilidade ao risco de contaminação dos recursos hídricos subterrâneos do município de Piratini-RS. Revista Monografias Ambientais. v. 13. p. 3977-3985. 2014.

COSTA, A. M. R.; WAICHMAN, A.; SANTOS, E. E. A. Uso e qualidade da água subterrânea na cidade de Manaus. In: SUPLEMENTO -XIII Congresso Brasileiro de Águas Subterrâneas. Cuiabá/MT. p. 1-18. 2014. 
COSTA, M. S. B.; PINTO, V. A. B.; SOARES, C. B. S. S. Análise do desmatamento nas zonas leste, norte e oeste da área urbana de Manaus/AM. IV Simpósio Brasileiro de Ciências Geodésicas e Tecnologias da Geoinformação. Recife/PE, p. 001 - 009. 2012.

COSTA, T. A. C. R.; OLIVEIRA, B. O. S.; VALENTE, K. S. Avaliação da qualidade de águas de poços cacimbas e rasos no município de Humaitá-AM. Revista EDUCAmazônia. v. 20, n. 1, p.157-172. 2018.

CPRM - Companhia de Pesquisa de Recursos Minerais, 2019. Disponível em: http://geosgb.cprm.gov.br/, Acesso em: 04/01/2019.

CUNHA P. R. C.; GONCALVES J. H. M. Bacia do Amazonas. Boletim de Geociências da PETROBRÁS. v. 15, n. 2, p. 227-251. 2007.

CUTRIM, A. O.; CAMPOS, J. E. G. Avaliação da vulnerabilidade e perigo à contaminação do Aquífero Furnas na cidade de Rondonópolis (MT) com aplicação dos métodos GOD e POSH. Revista Geociências, v. 29, n. 3. 2010.

DUARTE, M. L.; LOCATELLI, M.; SILVA FILHO, E. P. Vulnerabilidade à contaminação do aquífero Alter do Chão em sua área de afloramento no município de Itacoatiara/ AM. ACTA Geográfica. v.12, n.30, p 90-107. 2018.

DUARTE, M. L.; LOCATELLI, M.; SILVA, T. A.; SILVA FILHO, E. P. Vulnerabilidade à contaminação das águas subterrâneas do sistema de aquífero Içá/Fraturado Norte na área urbana do município de Porto Velho/Rondônia. REA - Revista de estudos ambientais. v.19, n. 2, p.4054. 2017.

DUARTE, M. L.; ZANCHI, F. B.; NEVES, J. R. D.; COSTA, S. C; JORDÃO, W. H. C. Vulnerabilidade à contaminação das águas subterrâneas no município de Humaitá, Amazonas, Brasil. Revista Ambiente \& Água. v. 11. n. 2. p. 402-413. 2016.

FERON, G. L.; REGINATO, P. A. R. Avaliação da vulnerabilidade de aquíferos localizados na região central de Canoas - RS. Revista Águas Subterrâneas, v. 28. p. 1-13. 2014.

FOSTER, S; HIRATA, R. Groundwater pollution risk assessment: a methodology using available data. WHO/ PAHO/HPECEPIS, Lima, (Relatório Técnico). p. 81. 1988.

FOSTER, S.; HIRATA, R; GOMES, D.; D’ELIA, M; PARIS, M. Proteção da Qualidade da Água Subterrânea: um guia para empresas de abastecimento de água, órgãos municipais e agências ambientais. São Paulo, Servemar, p.15-81. 2016.
IBGE - Instituto Brasileiro de Geografia e Estatistica. 2018. Amazonas, Manaus: Estimativa da população 2018. Disponível em: https://cidades.ibge.gov.br/brasil/am/ manaus/panorama, Acesso em: 08/01/2019.

IMPLURB - Instituto Municipal de Planejamento Urbano. 2018. Planejamento Urbano/Mapas Temáticos. Disponível em: http://implurb.manaus.am.gov.br/mapas-tematicos/ Acesso em: 10/02/2018.

INSAF, S.; BABIKER.; MOHAMED, A. A. M.; HIYAMA, T.; KATO, K. A GIS-based DRASTIC model for assessing aquifer vulnerability in Kakamigahara Heights, Gifu Prefecture, central Japan. Hydrospheric Atmospheric Research Center. v. 345. p. 127-140. 2005.

JÚNIOR, L. C. P.; SOARES, H. L. T.; CASTRO, S. S. Vulnerabilidade natural e risco de contaminação do aquífero Bauru no município de Rio Verde - GO. . v. 29, n. 2. p. 129-145. 2015.

MAIA, M. A. M. Geodiversidade do estado do Amazonas/ Organização técnica Maria Adelaide Mansini Maia [et al]; CPRM - Serviço Geológico do Brasil - Manaus. p. 59-71. 2010.

MEIRA, J. C. R.; DE-CAMPOS, A. B.; PEREIRA, L. C. Vulnerabilidade natural e perigo à contaminação de zona de recarga do aquífero Guarani. Águas Subterrâneas. v. 28, n. 1, p. 31-46. 2014.

OLIVEIRA A. I. L.; FRANÇA-ROCHA W. J. S. A. Modelagem da vulnerabilidade à contaminação de aquíferos livres em regiões hidrográficas do semiárido baiano explorada pela agroindústria. In: XVI Simpósio Brasileiro de Sensoriamento Remoto - SBSR, Foz do Iguaçu PR, Brasil. Anais... p. 6214 - 6221. 2013.

RABELLO, R. P.; RODRIGUES, Z. A. L. Planejamento e sustentabilidade urbana: ações de proteção dos igarapés de Manaus. Revista Meio Ambiente e Sustentabilidade. v.3 n.2, p.80-101. 2013.

REGINATO, P. A.; AHLERT, S. Vulnerabilidade do sistema Aquífero Serra Geral na região norte do estado do Rio Grande do Sul. Revista Águas Subterrâneas. v. 27. p. 32-46. 2013.

RIBEIRO, D. M.; ROCHA, W. F.; GARCIA, A. J. V. Vulnerabilidade Natural à contaminação dos aquíferos da Sub-bacia do Rio Siriri, Sergipe. Revista Águas Subterrâneas, v. 25. N. 1, p. 91-102. 2011.

SANTANA, G. P.; BARRONCAS, P. S. R. Estudo de metais pesados (Co, Cu, Fe, Cr, Ni Mn, Pb, e Zn) na Bacia do Tarumã Manaus - (AM). Acta Amazonica. v. 37. p. 111-118. 2007. 
SANTANA, G. P.; ZEFERINO, V. O. Avaliação da qualidade das águas subterrâneas usadas em escolas da rede estadual de ensino de Manaus. Caminhos de Geografia. v. 9, n. 25. p. 24-36. 2008.

SANTOS, R. A.; CRUZ, M. J. M.; NASCIMENTO, S. A. M. Avaliação da vulnerabilidade natural de aquíferos cársticos: Subsídios para uma gestão dos recursos hídricos subterrâneos. Cadernos de Geociências, n, 7. p. 54-62. 2010.

SIAGAS, Sistema de Informação de Águas Subterrâneas. 2019. Disponível em: http://siagasweb.cprm.gov.br, Acesso em: 10/01/2019.

SILVA, M. L.; BONOTTO, D. M. Caracterização hidrogeoquímica na Formação Alter do Chão, Município de Manaus (AM). $1^{\circ}$ Joint World Congresso on Groundwater. 2000, Fortaleza. CDROM of the 1st Joint World Congress on Groundwater. São Paulo: ABAS, p. 1-20. 2000.

SILVÉRIO DA SILVA, J. L.; NASCIMENTO, L. M.; LOBLER C. A. Mapeamento das águas subterrâneas do município de Boa Vista do Cadeado/RS. Revista Monografias Ambientais. v. 14. p. 3061-374. 2014.

SOUZA L. S. B. Mapeamento de aquíferos da cidade de Manaus (AM) - utilizando perfilagem geofísica de poço e sondagem elétrica vertical. Revista Brasileira de Geofísica. v. 24 p. 443. 2006.

SRTM - Shuttle Radar Topography Mission. Disponível em: http://srtm.usgs.gov/data/obtainingdata.html. Acesso em: 20/02/1019. 